\title{
Preventable gynecological surgeries in hysterectomized women : a review of causes and measures of prevention
}

\author{
Monika Anant* \\ Department of Obstetrics and Gynecology, All India Institute of Medical Sciences, Patna, Bihar, India \\ Received: 06 January 2019 \\ Accepted: 05 February 2019 \\ *Correspondence: \\ Dr. Monika Anant, \\ E-mail: drmonika.anant@gmail.com \\ Copyright: (C) the author(s), publisher and licensee Medip Academy. This is an open-access article distributed under \\ the terms of the Creative Commons Attribution Non-Commercial License, which permits unrestricted non-commercial \\ use, distribution, and reproduction in any medium, provided the original work is properly cited.
}

\begin{abstract}
Background: Hysterectomy, the most common gynaecologic surgery performed around the world. however, repeat gynaecologic intervention / surgery may be required for some conditions, adding cost and morbidity for patients and posing a burden on healthcare systems. The objective of the present study was to find out the incidence of and types of surgical intervention required post hysterectomy.

Methods: A retrospective analysis of hospital records was done for gynecologic operative procedures done in post hysterectomy patients 2014-2016.

Results: Out of a total of 1028 in the year 2014-2016 in our centre, 75 (7.3\%) surgeries were performed for benign conditions in hysterectomized women. Hydrosalpinx(29\%) was most common condition for surgery, followed by endometriosis $(24 \%$ ) with $31-40$ years age group women undergoing the maximum surgeries. Vault prolapse(16\%) in elderly and vaginal vault granulation $(16 \%)$ in younger women also underwent a repeat gynecological procedure post hysterectomy.

Conclusions: Some measures can be taken during the primary surgery(hysterectomy) to prevent a repeat gynaecological surgery in these women. Concurrent salpingectomy can prevent benign and malignant fallopian tube lesions and ovarian cancer. Endometriosis surgery should be precise to prevent any remnant ovarian or endometriotic foci. McCall's culdoplasty in primary hysterectomy is proven to prevent vaginal vault prolapse. Most genitourinary fistulas can be prevented by detailed knowledge of pelvic anatomy, preoperative risk stratification of patients at higher risk of ureteric and urinary bladder injuries, meticulous surgical technique and judicious use of electrosurgical energy. Prevention is always better than a repeat surgery.
\end{abstract}

Keywords: Endometriosis, Fallopian tube, Gynaecological surgery, Hysterectomy, Ovarian cancer

\section{INTRODUCTION}

Hysterectomy is the most commonly performed major gynaecologic surgery around the globe. The number of hysterectomies in India is lower than many developed countries probably because of lack of data rather than the number of cases. In the United States, approximately 600,000 hysterectomies are performed each year. ${ }^{1}$

The mean age of women undergoing hysterectomy is much lower In India. Whereas it is 55-65 years in the
United States and United Kingdom, in India it is 30-40 years only, and even more significantly lower in some states (24 years). ${ }^{2}$ Because of lower ages at hysterectomy, ovaries and fallopian tubes are usually preserved. With functional adnexa and 10-20 years of reproductive age remaining and increasing life expectancy of women, there are increased chances of development of many new conditions after surgery or persistence/ aggravation of pre-existing ones, which warrant further gynaecologic consultations and sometimes a repeat surgery. Many conditions are treatable medically like immediate post- 
operative infections, urinary tract disorders, chronic pelvic infections etc. The commonest immediate postoperative complications of SSI and wound resuturing has not been dealt with in this paper. This article reviews literature regarding conditions post hysterectomy which required further surgical management by a gynaecologist, their causes and prevention at the time of initial hysterectomy.

\section{METHODS}

A retrospective analysis of case records was done in Department of Obstetrics and Gynaecology, AIIMS Patna. All operated cases sheets were screened for a cohort of women who were operated for post hysterectomy benign conditions in the year 20142016.The case records of all patients were reviewed in context of their presentation, diagnosis and indications for surgery.

\section{Exclusion criteria}

- The immediate complications post hysterectomy which required care at our institute like surgical site infections, repeat malignancy surgery for incomplete staging done earlier.

Because AIIMS Patna is a relatively new institute, out of the studied cohort of 75 surgeries in post-hysterectomy cases only $2 / 75(2.7 \%)$ patients had had their initial hysterectomy in this institute, rest 73/75 (97.3\%) were hysterectomised elsewhere and had presented to AIIMS with their present complaints. The major conditions which were noted in this cohort of women were benign ovarian masses, tubal lesions, vaginal vault prolapse, vesicovaginal fistulas and vault granulation tissue.

\section{RESULTS}

The interval of presentation and decision for surgery and the primary hysterectomy surgery ranged from few weeks (vesicovaginal fistula, granulation tissue), few months (ovarian cyst / hydrosalpinx / endometriosis) to years (vault prolapse).

Table 1: Interval of presentation and decision for surgery.

\begin{tabular}{|c|c|}
\hline $\begin{array}{l}\text { Time of } \\
\text { presentation }\end{array}$ & Condition \\
\hline Days to weeks & $\begin{array}{l}\text { Vesico-vaginal fistula, granulation } \\
\text { tissue }\end{array}$ \\
\hline Months & $\begin{array}{l}\text { Ovarian cysts, hydrosalpinges, } \\
\text { endometriosis }\end{array}$ \\
\hline Years & Vault/ vaginal wall prolapse \\
\hline
\end{tabular}

Greatest number $(37 / 75,49.3 \%)$ of women in reproductive age (31-40 years) and $11 / 75$ (14.7\%) were are even less than 30 years. The commonest presentation was pain in lower abdomen and adnexal pathology was diagnosed in $47 / 75(62.6 \%)$ of cases amongst which ovarian cysts, endometriosis and hydrosalpinx were present.

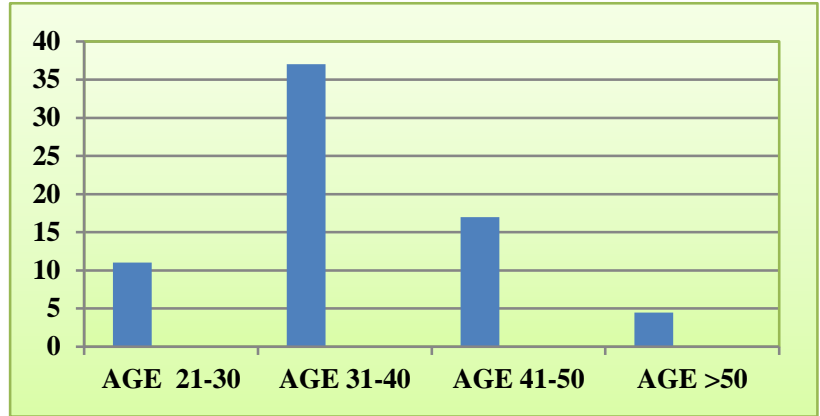

Figure 1: Age wise distribution of cases.

The cause for pain in endometriosis is obvious but in other conditions it was mostly adhesions in pelvis which caused the pain. The younger patients mostly had vault granulation tissue and endometriosis, whereas those $>50$ years had pelvic organ prolapse (Table 2).

Table 2: Presenting complaints and conditions/ indication of surgery.

\begin{tabular}{|l|l|l|l|}
\hline Condition & Operation & Frequency & Presentation \\
\hline Ovarian cyst & 16 & $21.3 \%$ & \\
\hline Endometriosis & 5 & $6.7 \%$ & \multirow{2}{*}{ Pain abdomen } \\
\hline PID: To mass & 7 & $9.3 \%$ & \\
\hline Benign cyst & 0 & & \\
\hline $\begin{array}{l}\text { Malignancy } \\
\text { Parovarian cyst }\end{array}$ & 1 & $1.33 \%$ & Pain lower abdomen \\
\hline Tubal & 18 & $24 \%$ & \\
\hline Hydrosalpinx & & & Vaginal discharge + bleeding \\
\hline $\begin{array}{l}\text { Vaginal } \\
\text { Vault granulation tissue }\end{array}$ & 12 & $16 \%$ & Continuous urinary leak \\
\hline VVF & 4 & $5.3 \%$ & Bulge sensation/something coming out PV \\
\hline Vault prolapse & 12 & $16 \%$ & \\
\hline
\end{tabular}




\section{DISCUSSION}

Hysterectomized patients that gynecologists encounter present with multitudes of problems although they form a smaller proportion of all gynecologic consults. Immediate complications after hysterectomy are about $1-2 \%$ and can be categorized into infectious, thromboembolic, genitourinary (GU) and gastrointestinal (GI) tract injury, bleeding, nerve injury, and vaginal cuff dehiscence. The most commonly encountered in our set up are the infectious complications with surgical site infections as high as $20 \%$. Injury to genitourinary tract $(1 \%)$ is more common than injury to gastrointestinal tract. Venous thrombo-embolism is less commonly encountered than the rest of the causes. Vaginal cuff dehiscence is estimated at a rate of $0.4 \%$ and is more common after total laparoscopic hysterectomy $(1.35 \%)$ than either abdominal or vaginal routes. 3

Among the delayed complications following hysterectomy women can suffer from bothersome psychosexual functions and increased incidence of vaginal prolapse. Ovarian endocrinal function also seems to wean off more rapidly and the mean age of onset of menopause is 3.7 years earlier than average, even when the ovaries are preserved 4.

Symptomatology of hysterectomized patients to our clinics ranged from dysuria, genital itching, dryness and other menopausal symptoms, vaginal spotting /discharge, abdominal pain and vaginal bulge.

Many patients presenting with vaginal discharge and intermittent bleeding after hysterectomy were due to formation of granulation tissue usually present within weeks of hysterectomy. They were treated with local antibiotics and antiseptics after a high vaginal swab. Vault granulation tissue with size smaller than $0.5 \mathrm{~cm}$ were chemically cauterized (copper sulphate crystals, silver nitrate). Lesions larger than $0.5 \mathrm{~cm}$ were taken up for excision biopsy. Two cases had sutures protruding through the granulation tissue which were removed without damage to the vaginal vault. Fimbrial prolapse was suspected in 3 cases but histopathology of the biopsied mass showed granulation tissue.

Patients presenting with abdominal pain underwent proper work up with clinical examination, urine analysis, imaging and ovarian tumor marker studies. On being diagnosed as benign tubo ovarian masses, suitable antibiotic therapy for chronic pelvic inflammatory disease was undertaken. Those who did not respond either in symptoms or size of mass were taken up for laparoscopy or laparotomy for excision of adnexal mass. Hydrosalphinx diagnosed on ultrasound were followed up with regular scans, patients who had unremitting pain or increase in size were operated. None of the patients had any suspected malignancy nor any histopathological features of dysplasia among the ovarian, tubal specimens. Four vesicovaginal fistulas were encountered, 1/4 was done in the institute for a 24 weeks size large adherent broad ligament fibroid. All of the patients except one had presented within 8-10 days of hysterectomy. It is a wellknown complication of hysterectomy but has been included in this study because there are simple and easy steps by which this iatrogenic condition can be prevented.

Sensation of vaginal bulge and mass outside introitus were the main presenting complaints of patients with prolapse occurring after hysterectomy. For some patients it was a pre-existent vaginal prolapse not corrected at primary surgery while others had complete vault prolapse (equal to total vaginal length ) post hysterectomy. These patients presented years after the primary surgery. 12 (16\%) patients of vaginal vault prolapse were operated by open abdominal salcralcolpopexy with interposition of synthetic mesh to anatomically restore the position of the vault.

\section{Prevention}

\section{Hydrosalpinx}

Hydrosalpinx is one condition which can be easily and defitinely prevented from developing in hysterectomised patients. Fallopian tubes should be removed even if ovaries are retained during operations for benign conditions .It is beneficial to remove the fallopian tubes as retaining them during hysterectomy for benign conditions doubles the risk for later surgery of adnexae5 Recent evidence has revolutionized the various previous theories towards the genesis of epithelial ovarian cancers from tubal epithelial shedding from the fimbrial end of fallopian tubes. Fallopian tubes have been shown to harbor premalignant cells. If fallopian tubes are removed during surgery for benign disease, for example in women in whom hysterectomy is indicated, these premalignant cells will be removed too. Such "prophylactic" or "opportunistic" salpingectomy procedures could prevent ovarian cancer development in later years. ${ }^{6}$ Prophylactic removal of the Fallopian tubes during hysterectomy or sterilization also rules out any subsequent tubal pathology, such as hydrosalpinx, which is observed in up to $30 \%$ of women after hysterectomy. The fallopian tubes also does not affect the ovarian hormone production. There is no known physiological benefit of retaining the fallopian tube during hysterectomy in the postreproductive years. But the ovaries definitely need to be preserved in premenopausal women as their early removal will result in surgical menopausal consequences on women's health.

Some researchers have even recommended offering bilateral salpingectomy as means of sterilization in women over 35 years of age for the additional benefit of ovarian cancer and other tubal pathology prevention. ${ }^{7}$

This cancer prevention approach does not increase the risk of operative/perioperative complications. Salpingectomy is a safe and feasible procedure during 
hysterectomy . A significant increase in operating time for salpingectomy with hysterectomy (16 minutes) and with sterilization (10 mins) does occur. Other than these , no significant differences in length of hospital stay, readmissions and or blood transfusion were identified in the cases with and without salpingectomy in a study by McAlpine et al. ${ }^{8}$

Benefit of this opportunistic salpingectomy is manifold, prevention of development of hydrosalpinx which may require prolonged surveillance, ultrasound and guided aspiration or surgical intervention, fallopian tube tumors, fimbrial prolapse and also later development of serous ovarian cancers.

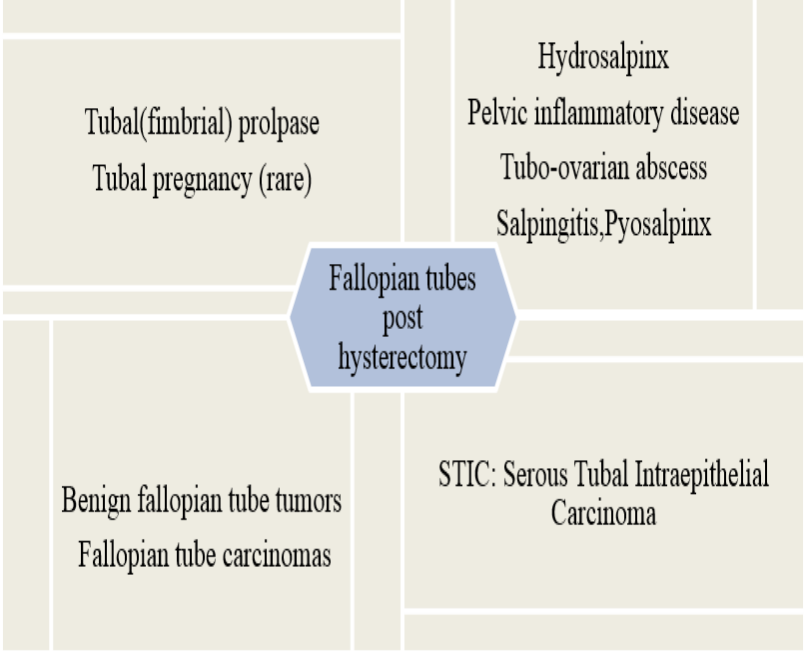

Figure 2: Complications in fallopian tubes post hysterectomy.

\section{Conditions related to ovary}

Post hysterectomy there might be development of ovarian masses due to endometriosis, infectious ovarian mass or abscess, benign or malignant tumors.

\section{Endometriosis}

An enigmatic disease sometimes not cured even by complete removal of uterus, tubes and ovaries. Remnant endometriotic foci in the pelvic peritoneum can produce its effect even in absence of recognizable ovarian tissue. The symptoms in endometriosis post-surgery is directly related to the amount of leftover disease. The greater the surgical precision and removal of peritoneal and deeply infiltrated (rectovaginal, ureteral) disease the better the symptomatic outcome.

Conservation of ovaries is usually not done for any case being operated for endometriosis but sometimes in women who are very young $(<30$ years), it may be considered weighing the patient's age and the impact of early menopause on her lifestyle. But in such cases of ovarian conservation, a very high recurrence rate of $62 \%$ has been reported in advanced stages of endometriosis . Ovarian conservation in endometriosis patients puts them at a 6-fold increased risk of recurrent pain and 8 folds increased risk of reoperation. ${ }^{9}$

Risk of recurrence in endometriosis patients can be minimized by a complete eradication of all visible endometriotic lesions with pan hysterectomy. Surgical effort should always aim to eradicate the endometriotic lesions completely to keep the risk of recurrence as low as possible. It has also been reported that women operated for endometriosis who have been given HRT are more at risk of endometriosis recurrence and reoperation. A much greater level of surgical expertise and precision is required in endometriosis surgery. Most cases of disease recurrence after hysterectomy are actually cases of disease persistence, so careful primary surgery should be the goal.

Infective conditions of tubes and ovaries (TO mass, TO abscess)

Gynecologic procedures pose a unique challenge in which possible pathogenic microorganisms of the skin, vagina and endocervix can easily migrate to vaginal or abdominal operative sites. This can cause post-operative vaginal cuff cellulitis, pelvic cellulitis, and pelvic abscesses. $^{10}$

Such infections in the pelvis and in the operative incision sites on the abdomen, perineum, or vagina can occur in the immediate postoperative period or even days after discharge from the hospital. Almost 50 per cent of these infections may occur after the patient is discharged from the hospital and can present much later. ${ }^{11}$

Patients at high risk are those having such as those with anemia, obesity ,diabetes, debilitating disease, advanced age, malnutrition, corticosteroid use, pre-operative CVA and bacterial vaginosis. Evaluation for preoperative and postoperative risk factors and managing modifiable risk factors can decrease infection rates. Therefore, preoperative screening for vaginal and vulval infection and treatment is an important deterrent to postoperative infection. $^{12}$

Prolonged preoperative hospitalization should be avoided to decrease the risk of patients becoming colonized with nosocomial bacteria, as these microorganisms tend to be more resistant to antibiotics compared to endogenous bacteria.

Huge gaps in gynecological care also enhance the complications caused by sexually transmitted infections. In most of the cases of vaginitis and cervicitis presenting with vaginal discharge, partners are not treated, and regular and effective gynecological treatment is also lacking. Improved education, routine screening, diagnosis, and empirical treatment of chlamydial and gonococcal infections should reduce their incidence and 
prevalence and the development of long-term sequelae. Patients are hysterectomised in unclean unhygienic clinics across India. Proper asepsis is lacking added to Improper selection of antibiotics and incomplete course of therapy ,leading to infective sequalae. Pelvic cellulitis or abscess remain untreated or incompletely treated in many cases leading to long term consequences of chronic tubo-ovarian abscess or masses. These patients usually present with intermittent fever and abdominal pain. These long-standing cases also do not respond to antibiotics and usually require surgical removal of the infective foci.

\section{Benign $n$ malignant ovarian tumor}

Removal of ovaries along with uterus during hysterectomy for benign uterine conditions can prevent development of ovarian cancer and other surgical procedures for benign ovarian masses. However, it also carries a negative health impact on the women due to surgical menopause. Numerous reports link oophorectomy to higher rates of cardiovascular disease, osteoporosis, hip fracture, dementia, short-term memory impairment, declines in sexual function, decreased positive psychological well-being, adverse skin and body composition changes, and adverse ocular changes, as well as more severe menopausal symptoms and urogenital atrophy. ${ }^{13}$ Prophylactic oophorectomy is often recommended concurrent with hysterectomy for benign disease. The optimal age for this recommendation in women not at high risk for ovarian cancer has not been determined. Earlier studies were in favor of ovarian removal. It is estimated that approximately 1,000 cases of ovarian cancer can be prevented if prophylactic oophorectomy is pre-formed in all women older than 40 years who undergo hysterectomy. ${ }^{14}$

Later ovarian conservation was related to the level of risk of ovarian cancer in in women. For women with an average risk of ovarian cancer, ovarian conservation until at least age 65 seems to benefit long-term survival. ${ }^{15}$

More recent researches are not definitive about decision to retain or remove ovaries in benign condition hysterectomy. A Cochrane review could not provide evidence to support removal or conservation of the ovaries at the time of hysterectomy in premenopausal women due lack of studies. Therefore, caution should be exercised until evidence regarding prophylactic removal of the ovaries is available. ${ }^{16}$ Hence, all patients need to be counselled in detail before the surgery regarding the pros and cons of retaining the ovaries at the time of hysterectomy. ACOG also recommends in favor of retaining normal ovaries in premenopausal women who are not at increased genetic risk of ovarian cancer. In women with endometriosis, pelvic inflammatory disease, and chronic pelvic pain a decision should be taken after balancing the risk of reoperation vs the benefits of ovarian retention. If opportunistic salpingectomy were to be carried out immediately in all hysterectomy procedures and would thereby prevent the development of all serous cancers, the incidence of ovarian cancer would be reduced by around $2.3 \%$ in 20 years if all hysterectomies were carried out together with bilateral salpingectomies and thus all serous cancers could be prevented. ${ }^{8}$

\section{Prevention of vaginal vault prolapse}

Post hysterectomy vaginal vault prolapse is a preventable complication. The overall incidence of prolapse after hysterectomy has been reported to be 3.6 per 1,000 women-years. ${ }^{17}$ The cumulative incidence of PFR after hysterectomy was $5.1 \%$ by 30 years. ${ }^{18}$

History of POP at the time of hysterectomy has consistently been shown as a strong and independent predictor of POP recurrence. There is a five times higher risk of prolapse after hysterectomy if the initial hysterectomy was performed for prolapse.

The risk factors which predispose to (growth and development, genetic factors, connective tissue weakness, joint mobility) and incite (childbirth, pelvic surgery, age related changes) prolapse will remain unaltered before and after hysterectomy but factors such as obesity, constipation, co-morbidities, heavy occupational work and vigorous physical activity needs to be addressed for prevention of vault prolapse. Conservative interventions include physical interventions to improve the function and support of the pelvic floor muscles (via pelvic floor muscle training) and mechanical interventions ( vaginal pessaries) to support the prolapse. However, there is no evidence to suggest whether pelvic-floor exercises are helpful in vault prolapse. ${ }^{19}$

Various adjunctive procedures during initial hysterectomy has been described and practiced for prevention of vaginal vault prolapse since long time. Miller described the attachment of the USL to the vaginal vault for support. McCall described passing a suture from one side of the vaginal cuff and USL through the peritoneum to the other side, effectively closing the culde-sac. Shull et al described a "high" uterosacral ligament suspension to attach a strong segment of the USL to the rectovaginal and anterior pubocervical fascia. ${ }^{20}$

McCall's culdoplasty may be performed at the time of vaginal hysterectomy for non-prolapse related disease to reduce the risk of postoperative apical prolapse for up to 3 years (Level B evidence). Uterosacral ligament suspension may be performed at the time of abdominal (Level B) and laparoscopic (Level C) hysterectomy to reduce the risk of post- hysterectomy vaginal vault prolapse. Sacrospinous ligament fixation and abdominal sacral colpopexy are not recommended for the prevention of prolapse at the time of hysterectomy for non-prolapse related disease (Level C). ${ }^{21}$

Prophylactic sacrospinous fixation has been suggested at the time of vaginal hysterectomy for marked uterovaginal 
prolapse, when the vault could be pulled to the introitus at the end of anterior vaginal wall closure, which is a selected subgroup of those undergoing vaginal hysterectomy. But, sacrospinous ligament fixation and abdominal sacral colpopexy are not recommended for the prevention of prolapse at the time of hysterectomy for non-prolapse related disease. (Level C). Mc Call's culdoplasty has been found to be superior in preventing subsequent apical prolapse after vaginal hysterectomy than with either peritoneal closure more the vaginal Moschowitz procedure. ${ }^{22}$ Similar procedures have been described for use during abdominal and laparoscopic hysterectomy. ${ }^{23}$

An alteration in the level of the fibers of the paracolpium (level I) which suspend the upper third of the vagina could modify vault suspension. Suturing the cardinal and uterosacral ligaments to the vaginal cuff at the time of hysterectomy is a recommended measure to avoid vault prolapse. ${ }^{24,25}$ Hence, for prevention of vaginal vault prolapse:

- Fixation of vaginal vault to a strong pelvic ligament

- Obliteration and repair of cul-de-sac.

- Proper selection of suture material eg. Polypropelene or delayed absorbable polydioxamine, are important points of consideration. ${ }^{26}$

\section{Vault granulation tissue}

The scar tissue at the vaginal cuff after hysterectomy can have connective and/or vascular granulation tissue which is a normal healing process. A longer time for healing can cause persistence of granulation tissue at the vaginal vault and symptoms of vaginal discharge or bleeding or both in few patients. Vault granulation tissue is a common and neglected complication of hysterectomy. It occurs in about one-third of patients who had total abdominal hysterectomy. ${ }^{27}$

Cuff cellulitis, early sexual intercourse, cigarette smoking, poor nutrition, obesity, menopausal status, and corticosteroid use are all proposed risk factors that promote infection, pressure at the vaginal cuff, and poor wound healing. Diabetes Mellitus may also be a risk factor for forming granulation tissue due to delayed wound healing.

The severity of the vaginal discharge and the patient's desire for early intervention are important considerations in selecting a clinical strategy. If the lesions are small (< or $=5 \mathrm{~mm}$ ) a policy of wait and watch is to be adopted as few give symptoms and most regress spontaneously. Cauterization of the granulation tissue and antibiotic treatment is always a therapeutic option. Cauterisation can be thermal, electrical or chemical. Commonly used is chemical cautery is by Silver nitrate or copper sulphate crystals . Sometimes, removal of all vaginally exposed suture is required to achieve complete resolution. Rarely surgical intervention in the operating room may be necessary. $\mathrm{CO}_{2}$ laser vaporization under colposcopic and laparoscopic guidance for the treatment of persistent granulation tissue has also been reported for case of recurrent vaginal mesh erosion. ${ }^{28}$ The development of vault granulation tissue can be prevented by proper technique of suturing the vault, optimum suture material and infection prevention.

The open vault technique had a much higher granulation tissue formation rate. As early as 1990's it was found that polygalactide, a synthetic polymer, is associated with fewer vaginal vault granulations than chromic catgut. ${ }^{29}$ Staplers (absorbable) also has lower frequency of postoperative granulation tissue at the apex of the vaginal vault and vaginal discharge during 12 weeks of followup. ${ }^{30}$ Siedhoff et al have observed a lower incidence of vaginal cuff dehiscence, postoperative bleeding, presence of granulation tissue and cuff cellulitis when bidirectional barbed suture was used in the laparoscopic vaginal suturing after hysterectomy and trachelectomy. ${ }^{31}$ Laparoscopic route have been found to have lower incidence of forming granulation tissue (6.4\%) compare to historical data. This in view of the researchers may be due to the intraperitoneal placement of suture knot, causes less exposure of vaginal epithelium to the suture material. ${ }^{32}$ Treating any pre-operative vaginal infection also lowers the incidence of post-operative vaginal infection, discharge and persistence of granulation tissue.

\section{Prevention of $\mathrm{VVF}$}

Urogenital fistula are not that uncommon complication of hysterectomy. The general incidence of ureteral injuries is estimated to be $0.03 \%$ to $2.0 \%$ for abdominal hysterectomy, $0.02 \%$ to $0.5 \%$ for vaginal hysterectomy, and $0.2 \%$ to $6.0 \%$ for laparoscopy-assisted vaginal hysterectomy. ${ }^{33}$ Pelvic surgery is the most common cause of iatrogenic ureteral injury. During any pelvic surgery, the surgeon must have a thorough knowledge of the location of the ureter and the specific locations where it is most susceptible to injury to prevent ureteral injuries. ${ }^{34}$ The most common sites of ureteral injury are at the pelvic brim, near the infundibulopelvic ligament, by the uterosacral ligament under the uterine artery. Nearly $80 \%$ of ureteral injuries occur in close proximity to the uterine artery. Intraoperative injury to the ureter may result from ligation, angulation, transection, laceration, crush, ischemia, and resection. With regard to mode of hysterectomy, vaginal hysterectomy is reported to have a lower incidence of ureteral injury when compared with abdominal hysterectomy $(0.9 \%$ vs $1.7 \%) .{ }^{35}$ It is the lowest following vaginal hysterectomy for prolapse. There is a higher rate of recognized ureteral injury during total laparoscopic hysterectomy compared with other methods. $^{36}$

Some pelvic procedures are associated with higher rates of fistula formation like radical hysterectomy (1 in 87) as reported by Hilton et al. Younger women under 40 yrs of age undergoing hysterectomy for benign conditions like 
endometriosis, menstrual problems or fibroids have higher risk of fistula than women aged 50 years and above. ${ }^{37}$ The dome of the bladder is commonly involved in bladder injury during total hysterectomy. Whereas the bladder neck is at most risk during vaginal hysterectomy or anterior vaginal wall surgeries . Similar to ureteric injury , laparoscopic hysterectomy has highest incidence of bladder injury when compared to abdominal or vaginal routes. ${ }^{38}$

Recognizing the patients who are at higher risk of urinary tract injury will require preoperative risk assessment and additional imaging, ureteral stenting and a modified surgical plan to decrease the risk. Invasive cancer (5-8\%) or urogynecologic surgeries pose highest risk of injury to urinary tract. Hysterectomy for large uteri or cervical mass bring ureter closer and requires careful surgery . Distortion of pelvic anatomy occurs in large adnexal masses and pelvic adhesions (prior abdominopelvic surgery, pelvic radiation, PID, tuberculosis or advanced endometriosis) requiring meticulous adhesiolysis, ureter identification and isolation. In cases where there is a high clinical index of suspicion of ureteral anatomic distortion, preoperative imaging of the genitourinary tract is recommended. In patients with extensive pelvic adhesive disease, a full ureterolysis is usually safer.Patients with previous caesarean sections may have ureteric and bladder injury due to dense adhesions, should preferably undergo a sharp dissection technique. It has been suggested that during laparoscopic surgery specifically, the ureter is at greatest risk of injury at the IP ligament, in the ovarian fossa, and in the ureteric canal.

When performing a total laparoscopic hysterectomy, sufficient skeletonization of the uterine vasculature and tackling ascending uterine vessels at the level of the internal cervical os have been proposed to prevent ureteric injury. ${ }^{39}$ Cephalad pressure applied on the uterine manipulator during colpotomy will distance the ureter from the incision site and remain lateral to the vaginal cuff during closure. All electrosurgical devices should be used with great care, at the lowest possible power settings, and for the shortest possible duration to prevent damage to adjacent structures through lateral spread of thermal energy. ${ }^{40}$

Intraoperatively, recognizing the urinary tract injury and immediate repair is the best for a good outcome. Routine cystoscopy is not recommended for all laparoscopic hysterectomies as it identifies only $50 \%$ of injuries. Thermal injury presents late when injured tissue necrosed and sloughs off and is not recognized at intraopeartive cystoscopy.

\section{CONCLUSION}

Younger age at hysterectomy, surgical technique, conservation/ removal of ovary /fallopian tubes, route of procedure, condition of infection pre, during and post- operative leads to development of some conditions which may warrant further gynaecologic surgical intervention.

Many of these post-hysterectomy gynaecological surgical procedures are preventable. Conditions related to fallopian tubes and ovarian cancer can be easily avoided by salpingectomy concurrent to hysterectomy with retention of ovaries even in premenopausal women. Meticulous removal of all endometriosis by good surgical skill prevents any remnant ovarian or endometriotic foci.

Vaginal vault prolapse can be prevented by few simple steps in initial hysterectomy like McCall's culdoplasty. Iatrogenic genitourinary fistulas can be prevented by detailed knowledge of pelvic anatomy, preoperative risk stratification of patients at higher risk of ureteric and urinary bladder injuries, meticulous surgical technique and judicious use of electrosurgical energy. Prevention is better than repeat surgery.

Funding: No funding sources

Conflict of interest: None declared

Ethical approval: The study was approved by the Institutional Ethics Committee

\section{REFERENCES}

1. Wu JM, Wechter ME, Geller EJ, Nguyen TV, Visco AG. Hysterectomy rates in the United States, 2003. Obstet Gynecol. 2007;110(5):1091-5.

2. Desai S, Sinha T, Mahal A. Prevalence of hysterectomy among rural and urban women with and without health insurance in Gujarat, India. Reproduct Health Matters. 2011;19(37):42-51.

3. Clarke-Pearson DL, Geller EJ. Complications of hysterectomy. Obstet Gynecol. 2013;121(3):654-73.

4. Farquhar C.M, Sadler L, Harvey SA, Stewart AW. The association of hysterectomy and menopause : a prospective cohort study. Int J Obstet Gynaecol. 2005;112(7):956-62.

5. Vorwergk J, Radosa MP, Nicolaus K, Baus N, Cruz JJ, Rengsberger $M$, et al. Prophylactic bilateral salpingectomy (PBS) to reduce ovarian cancer risk incorporated in standard premenopausal hysterectomy: complications and re-operation rate. $\mathbf{J}$ Cancer Res Clin Oncol. 2014;140(5):859-65.

6. Pölcher M, Hauptmann S, Fotopoulou C, Schmalfeldt B, Meinhold-Heerlein I, Mustea A. et al Opportunistic salpingectomies for the prevention of a high-grade serous carcinoma: a statement by the Kommission Ovar of the AGO. Arch Gynecol Obstet. 2015;292(1):231-4.

7. Dietl J, Wischhusen J, Häusler SF. The postreproductive fallopian tube: better removed? Human Reproduct. 2011;26(11):2918-24.

8. McAlpine JN, Hanley GE, Woo MM, Tone AA, Rozenberg N, Swenerton KD et al. Opportunistic salpingectomy: uptake, risks, and complications of a regional initiative for ovarian cancer prevention. Am J Obstet Gynecol. 2014;210(5):471-e1. 
9. Rizk B, Fischer AS, Lotfy HA, Turki R, Zahed HA, Malik R. Recurrence of endometriosis after hysterectomy. Facts, Views Vision in Obstet Gynecol. 2014;6(4):219-27.

10. Lachiewicz MP, Moulton LJ, Jaiyeoba O. Pelvic surgical site infections in gynecologic surgery. Infectious diseases in obstetrics and gynecology. 2015;2015.

11. Hemsell DL. Infections after gynecologic surgery. Obstet Gynecol Clin North Am.1989;16(2):381-400.

12. Larsson PG, Carlsson B. Does pre-and postoperative metronidazole treatment lower vaginal cuff infection rate after abdominal hysterectomy among women with bacterial vaginosis? Infect Disease Obstetrics Gynecol. 2002;10(3):133-40.

13. Rocca WA, Grossardt BR, de Andrade M, Malkasian GD, Melton III LJ. Survival patterns after oophorectomy in premenopausal women: a population-based cohort study. Lancet Oncol. 2006;7(10):821-8.

14. Sightler SE, Boike GM, Estape RE, Averette HE. Ovarian cancer in women with prior hysterectomy: a 14-year experience at the University of Miami. Obstet Gynecol. 1991;78(4):681-4.

15. Shoupe D, Parker WH, Broder MS, Liu Z, Farquhar C, Berek JS. Elective oophorectomy for benign gynecological disorders. Menopause. 2007;14(3):580-5.

16. Orozco LJ, Salazar A, Clarke J, Tristán M. Hysterectomy versus hysterectomy plus oophorectomy for premenopausal women. Cochrane Database of Systematic Reviews. 2008(3).

17. Mant J, Painter R, Vessey M. Epidemiology of genital prolapse: observations from the Oxford Family Planning Association Study. Br J Obstet Gynaecol. 1997;104(5):579-85.

18. Blandon et al. Incidence of pelvic floor repair after hysterectomy: A population-based cohort study. Am J Obstet Gynecol. 2007;197(6):664.e1-e7.

19. Hagen S, Stark D, Maher C, Adams E. Conservative management of pelvic organ prolapse in women. Cochrane Database Syst Rev 2006;4:CD003882.

20. Worldwide AA. AAGL practice report: practice guidelines on the prevention of apical prolapse at the time of benign hysterectomy. Journal of minimally invasive gynecology. 2014 Sep 1;21(5):715-22.

21. Prolapse PH. Green-top Guideline No. 46 RCOG/BSUG Joint Guideline| 2015.

22. Cruikshank SH, Kovac SR. Randomized comparison of three surgical methods used at the time of vaginal hysterectomy to prevent posterior enterocele. Am J Obstetrics Gynecol. 1999;180(4):859-65.

23. Lin LL, Phelps JY, Liu CY. Laparoscopic vaginal vault suspension using uterosacral ligaments: a review of 133 cases. Journal of minimally invasive gynecology. 2005;12(3):216-20.

24. Margulies RU, Rogers MA, Morgan DM. Outcomes of transvaginal uterosacral ligament suspension: systematic review and metaanalysis. Am J Obstet Gynecol. 2010;202(2):124-34.
25. Rahn DD, Stone RJ, Vu AK, White AB, Wai CY. Abdominal hysterectomy with or without angle stitch: correlation with subsequent vaginal vault prolapse. Am J Obstet Gynecol. 2008;199(6):669-e1.

26. Sarma H. Post hysterectomy vault prolapse: A growing challenge for the gynaecologist. New Indian J Obstet Gynecol. 2015;2(1).

27. Saropala N., Ingsirorat C. Conservative treatment of vaginal vault granulation tissue following total abdominal hysterectomy. Int $\mathrm{J}$ Gynaecol Obstet. 1998;62(1):55-8.

28. Steinberg BJ, Mapp T, Mama S, Echols KT. Surgical treatment of persistent vaginal granulation tissue using $\mathrm{CO} 2$ laser vaporization under colposcopic and laparoscopic guidance. JSLS: J Soc Laparoendosco Surg. 2012;16(3):488.

29. Manyonda IT, Welch CR, Mcwhinney NA, Ross LD. The influence of suture material on vaginal vault granulations following abdominal hysterectomy. BJOG: Int J Obstet Gynaecol. 1990;97(7):608-12.

30. Kalbfleisch RE . Prospective randomized study to compare a closed vault technique using absorbable staples at the time of abdominal hysterectomy versus open vault technique. Surg Gynecol Obstet. 1992;175(4):337-40.

31. Siedhoff MT, Yunker AC, Steege JF. Decreased incidence of vaginal cuff dehiscence after laparoscopic closure with bidirectional barbed suture. J Minim Invasive Gynecol. 2011;18(2):218-23.

32. Azadi A, Lipetskaia L, Yeganeh T, Tate SB, Diaz SV. Granulation tissue formation at the vaginal cuff after total laparoscopic hysterectomy or Davinci assisted total hysterectomy with uterosacral ligament colpopexy for surgical correction of pelvic organ prolapse. J Minimal Invas Gynecol. 2011;18(6):S141.

33. Gilmour DT, Das S, Flowerdew G. Rates of urinary tract injury from gynecologic surgery and the role of intraoperative cystoscopy. Obstet Gynecol. 2006;107(6):1366-72.

34. Chan JK, Morrow J , Manetta A. Prevention of ureteral injuries in gynecologic surgery Am J ObstetGynecol 2003;188:1273-7.

35. Ibeanu OA, Chesson RR, Echols KT, Nieves M, Busangu F, Nolan TE. Urinary tract injury during hysterectomy based on universal cystoscopy. Obstet Gynecol. 2009;113(1):6-10.

36. Donnez O, Jadoul P, Squifflet J, Donnez J. A series of 3190 laparoscopic hysterectomies for benign disease from 1990 to 2006: evaluation of complications compared with vaginal and abdominal procedures. BJOG.2009;116(4):492-500.

37. Hilton P, Cromwell DA. The risk of vesicovaginal and urethrovaginal fistula after hysterectomy performed in the English National Health Service-a retrospective cohort study examining patterns of care between 2000 and 2008. BJOG: Int J Obstet Gynaecol. 2012 Nov;119(12):1447-54. 
38. Härkki-Sirén P, Sjöberg J, Tiitinen A. Urinary tract injuries after hysterectomy. Obstet Gynecol. 1998;92(1):113-18.

39. Manoucheri E, Cohen SL, Sandberg EM, Kibel AS, Jon Einarsson J. Ureteral Injury in Laparoscopic Gynecologic Surgery. Rev Obstet Gynecol. 2012;5(2):106-11.

40. Sutton PA, Awad S, Perkins AC, Lobo DN. Comparison of lateral thermal spread using monopolar and bipolar diathermy, the Harmonic
Scalpel and the Ligasure. Brit J Surg. 2010.97(3):428-33.

Cite this article as: Anant $M$. Preventable gynecological surgeries in hysterectomized women: a review of causes and measures of prevention. Int $\mathbf{J}$ Reprod Contracept Obstet Gynecol 2019;8:988-96. 